\title{
TOD@S SÃO TOD@S?
}

Aparecida Rangel ${ }^{1}$

\section{Justificativa}

O campo da Educação Museal desenvolve estudos e práticas que visam maior aproximação do público com a instituição. Proporcionar ao visitante uma experiência cultural diferenciada que possibilite aguçar o olhar, ampliar a capacidade crítica e sensibilizar para as questões relativas ao patrimônio, em seu sentido lato, é a missão a que se propõem os profissionais que atuam neste campo.

Diferentes segmentos de públicos visitam todos os dias as instituições museológicas e, por meio das denominadas pesquisas de público buscamos conhecer o perfil dessas pessoas, bem como seu grau de satisfação, demandas e expectativas em relação à instituição visitada. E, assim, vamos buscando construir um diálogo com o público externo almejando, de fato, transformar o museu em instituição “(...) aberta ao público, a serviço da sociedade e de seu desenvolvimento", como preconiza o estatuto de museus ${ }^{2}$. Nesse sentido, o trabalho desenvolvido pela educação museal é voltado para todos os cidadãos, mas estamos de fato conseguindo perceber nosso universo de possibilidades? Estamos alcançando todos os segmentos que pretendemos ou alguns nos escapam por nossa incapacidade de identificá-los como tal? Como estamos lidando com aqueles que, como nós, trabalham, direta ou indiretamente, na preservação dos acervos da instituição? As equipes que compõem os quadros de vigilância, limpeza, jardinagem e recepção são

Submetido em: 30/08/2019 Aceito em: 30/08/2019 Publicado em: 31/08/2019.

\footnotetext{
${ }^{1}$ Museu Casa de Rui Barbosa Brasil

2 Disponível em http://www.planalto.gov.br/ccivil 03/ Ato2007-2010/2009/Lei/L11904.htm. Acessado no dia 14/08/2014.
} 
privilegiadas pelos nossos projetos? Conhecemos os seus hábitos culturais? Esses funcionários entendem o seu papel nesta engrenagem de preservação? Ou, ainda, mais sério: sabem que atuam numa instituição de preservação?

São questões como estas que nos levaram a realizar a pesquisa intitulada "perfil/opinião dos funcionários das equipes terceirizadas" buscando identificar três:

Quais são seus hábitos culturais;

Grau de conhecimentos a respeito da natureza da instituição;

Tipo de relação que a instituição estabelece com eles e vice-versa;

\section{Contexto institucional}

A realização da pesquisa se insere num contexto institucional bastante difícil em função do esvaziamento do quadro marcado por aposentadorias e a impossibilidade de contratação de profissionais da área fim. E neste sentido o setor educativo do Museu Casa de Rui Barbosa que entre o final a década de 1970 e início de 1990 contava com oito funcionários ficou reduzido a uma única servidora de 2002 a 2014. Uma série de ações foi suprimida e outras ocorriam com o auxílio de estagiários e parcerias de variadas naturezas.

O programa de visitas mediadas foi mantido, sobretudo para o segmento escolar, enquanto que para o público espontâneo foram definidos dois horários, com atendimento somente nos somente nos fins de semana. Vale ressaltar que a visita mediada é uma demanda do público, muitos visitantes solicitam este serviço ao chegar à recepção, e outros entram em contato por telefone ou e-mail para saber se a instituição dispõe de tal atividade, sendo esta a razão do esforço para a continuidade do programa.

Os funcionários das equipes terceirizadas sempre receberam treinamento para atuar no interior do museu seja na limpeza e cuidados relativos aos acervos, como na forma de lidar com o público, em função da natureza do serviço realizado: limpeza, segurança ou recepção. Entretanto o trabalho que desenvolvíamos com estas pessoas era do âmbito técnico, não sendo elas inseridas em nosso escopo de preocupações como público visitante ou público potencial. Esta percepção se deu a partir da fala de uma funcionária da limpeza que verbalizou o desconhecimento sobre a necessidade de 


\section{Revista Docência e Cibercultura}

preservar um bem musealizado, pois para ela se um objeto fosse quebrado, "bastava comprar outro e jogar aquele fora". Aquele momento revelador despertou alguns questionamentos sobre a atuação da área educativa da instituição, na medida em que reconhecemos nas palavras da funcionária a inexistência de uma ação voltada para as pessoas que atuam na instituição museu por "obrigação", pois foram designadas para aquele posto sem que tivessem qualquer familiaridade com o local. Entretanto, esta é uma oportunidade de cativarmos estas pessoas para que se tornem público efetivo das instituições culturais e sejam divulgadores das ações desenvolvidas nos museus.

\section{A pesquisa}

A pesquisa foi realizada entre os meses de agosto e setembro de 2014, tendo como fonte para coleta dos dados um questionário desenvolvido pela idealizadora da mesma. As entrevistas foram gravadas e as perguntas realizadas por um servidor recémincorporado ao quadro, por meio de concurso público realizado em 2014. Esta escolha se deu por entendermos que a servidora que idealizou a pesquisa poderia causar inibição nos respondentes pelo tempo de convívio. O público alvo contemplou funcionários de empresas terceirizadas, sendo cinco prestados de serviço de jardinagem; duas recepcionistas; doze vigilantes; quatro auxiliares de serviços gerais e uma pessoa da área de manutenção. Dentre estes profissionais apenas os jardineiros trabalham na parte externa da residência história e, em função deste fato, incluímos uma questão sobre a natureza da instituição, sem mencionar que se tratava de um museu para aferir o conhecimento do respondente sobre o local. Foram entrevistadas vinte pessoas, pois duas não quiseram participar e, por questões logísticas não contemplamos os vigilantes noturnos.

Constatamos que dos vinte participantes, apenas dois haviam entrado em um museu, antes de trabalhar no Museu Casa de Rui Barbosa: falta de interesse, desconhecimento e imagem negativa foram às causas apontadas. A maioria afirmou que usava o tempo de lazer para dormir, embora desejassem fazer algo considerado mais interessante. Um pouco mais da metade apontou o desejo de participar de uma visita 
mediada como se "fosse um visitante". Uma participante expressou seu desconhecimento sobre a instituição museu ao revelar espanto ao ser designada para atuar no Museu, como vigilante, e encontrar "uma casa montada com cama, armário, sofá e outros itens", pois para ela "museu era um monte de quadros pendurados".

O material bruto possui cinco horas de gravação e revela elementos importantes para pensarmos as relações que as instituições estabelecem com seus funcionários e o quanto estes se ressentem por se sentirem a margem de alguns processos. O conteúdo também possibilita uma intensa reflexão sobre a forma como as experiências culturais estão sendo construídas por aqueles que, muitas vezes, desconhecem os equipamentos culturais e seus códigos de acesso. Esta breve resenha é fundamental para a compreensão do vídeo (disponível

em

<http://rubi.casaruibarbosa.gov.br/handle/20.500.11997/11843>) realizado em parceria com o, então, servidor da Fundação Casa de Rui Barbosa, Lucas Ferraço Nassif, pois contextualiza seu processo de produção e explicita que tal situação foi contingencial, servindo para a mudança de atitude em relação aos diferentes grupos que atuam na instituição. Esta pode ser pensada como uma engrenagem complexa cujo funcionamento depende da sincronização dos mecanismos que a compõem, representado pelo corpo funcional, sem hierarquizações. A sintonia, necessária, a reverberação pretendida junto à sociedade não surge espontaneamente, ela é também uma construção mediada pela instituição com a participação de todos os seus funcionários independente da categoria que estejam inseridos. A experiência vivenciada pelo visitante é impactada por diferentes elementos que podem contribuir de forma positiva ou não, para que ele retorne à instituição e, compartilhe sua emoção, tornando-se um divulgador do lugar.

\section{Pesquisa perfil-opinião}

Pesquisa a ser realizada com os funcionários das equipes de apoio do Museu Casa de Rui Barbosa (Vigilância; Serviços Gerais; Recepção e Jardinagem)

Agosto/2014 


\section{Questionário-base para entrevista e filmagem}

\section{1 - Identificação}

1.1 - Nome do entrevistado:

1.2 - Idade:

1.3-Sexo: ( ) Feminino ( )Masculino

1.4 - Bairro de residência:

1.5 - Estado civil:
( ) Solteiro
( ) Casado/união civil
( ) Divorciado/separado
( ) Viúvo
( ) União estável

1.6 - Nível de escolaridade:

( ) Sem instrução formal

( ) Ensino Fundamental $-1^{\circ}$ segmento completo $\left(1^{\circ}\right.$ ao $5^{\circ}$ ano $) /($ ) incompleto

( ) Ensino Fundamental $-2^{\circ}$ segmento completo $\left(6^{\circ}\right.$ ao $9^{\circ}$ ano $) /($ ) incompleto

( ) Ensino Médio completo / ( ) incompleto

( ) Ensino Superior completo / ( ) incompleto

( ) Pós-graduação

1.7 - Nome da empresa

1.8 - Tempo de atuação na empresa:

1.9 - Tempo de atuação no Museu Casa de Rui Barbosa:

\section{2 - Conhecimento sobre o Museu Casa de Rui Barbosa}

2.1 - Você sabe o que funciona nesta Casa Rosa?
( ) Não
( ) Sim : o que é?

2.2 - Já entrou alguma vez?

( ) Sim - para fazer o quê?

( ) Não - já teve curiosidade de entrar? ( ) Sim ( ) Não

2.3 - Quando alguém pergunta onde você trabalha, o quê responde?

2.4 - Considera importante o tipo de atividade que é desenvolvida nesta instituição? Por quê?

\section{3 - Relacionamento com a instituição}

3.1 - Já foi convidado pela instituição a participar de uma sessão de visita guiada?
( ) Sim
( ) Não

3.2 - Houve alguma atividade de apresentação do local para você?

( ) Sim - o que você achou?

( ) Não - você acha que deveria ter tido? 


\section{Revista Docência e Cibercultura}

3.4 - Trouxe algum parente ou amigo para visitar a instituição no seu dia de folga?

( ) Sim - Quantas vezes?

( ) Não

Por quê? ( ) É longe ( ) Não é interessante

( )

3.5 - Já indicou este lugar para algum parente ou amigo conhecer?

( ) Sim

( ) Não

3.7 - Que atividades a instituição poderia desenvolver para atrair a sua atenção?

\section{4 - Hábitos culturais}

4.1 - Qual o seu principal hábito de lazer?

4.2 - Por que este item apontado é o seu principal hábito de lazer?

4.2 - Antes de vir trabalhar aqui, você já tinha visitado algum museu?

( ) Sim - Quantas vezes?

( ) Não

Por quê? ( ) Não gosto （） Não conheço （）

4.3 - O fato de trabalhar neste lugar mudou sua visão pelo museu? De que forma?

4.5 - Você acha importante existir museu? Por quê? Servem para quê?

Nome do entrevistador:

Data:

Local da entrevista:

Apoio / função:

Equipamento de filmagem: 